\title{
Águas Urbanas no Plano Piloto: novas demandas por infraestrutura ecológica frente à escassez de recursos hídricos na Bacia do Lago Paranoá 1
}

\section{Urban Waters in the Pilot Plan: new demands for ecological infrastructure facing the scarcity of water resources in the Lago Paranoá Basin}

\author{
Gramacho, Raíssa; Andrade, Liza 2; Costa, Everaldo³ \\ I Faculdade de Arquitetura e Urbanismo - UnB, Instituto Central de Ciências - \\ ICC Norte - Gleba A, rai.gramacho@gmail.com \\ 2Faculdade de Arquitetura e Urbanismo - UnB, lizamsa@gmail.com \\ ${ }^{3}$ Departamento de Geografia - UnB, everaldocosta@unb.br
}

\begin{abstract}
RESUMO
Brasília nasceu dos discursos sonhadores e desenvolvimentistas, trazendo consigo o contexto social e ambiental presente nas grandes cidades da época, e reproduzindo relações de poder sobre a natureza. Quando transferida a capital, o projeto modernista não se adequou ao ciclo da água urbano e às novas técnicas de infraestrutura e, passados 59 anos, ainda observa-se a falta de planejamento provocando intervenções e construções onerosas, como as apresentadas pela NOVACAP para os problemas de drenagem urbana. Questiona-se atualmente a sustentabilidade da capital, e Brasília se encontra no embate entre gestores dos órgãos governamental e patrimonial a respeito das medidas para o enfrentamento dos problemas de drenagem bem como de proteção de solos e nascentes em todo DF. Assim, a pesquisa teve como objetivo encontrar argumentos - dentre os que determinam 0 tombamento do Plano Piloto - que possibilitam e justificam o uso de alternativas mais sustentáveis como os padrões espaciais de infraestruturas verdes para as regiões que apresentam enchentes nos picos de chuva. Foram investigadas as origens da cidade-parque, considerando a Escala Bucólica - dentro dos aspectos patrimoniais, históricos e simbólicos, e as demandas (água, energia, trabalho) e recursos (águas cinzas e negras, resíduo orgânico e reciclável).
\end{abstract}

Palavras-chave: Drenagem Urbana, Infraestrutura verde, Escala Bucólica, Patrimônio, Brasília Sensível à Água, Plano Piloto.

\section{ABSTRACT}

Brasilia was born of the dreamy and developmental discourses, bringing with it the social and environmental context present in the great cities of the time, and reproducing relations of

${ }^{1}$ GRAMACHO, R.; ANDRADE, L.; COSTA, E. Águas Urbanas no Plano Piloto: novas demandas por infraestrutura ecológica frente à escassez de recursos hídricos na Bacia do Lago Paranoá. In: II SIMPÓSIO NACIONAL DE GESTÃO E ENGENHARIA URBANA: SINGEURB, 2019, São Paulo. Anais... Porto Alegre: ANTAC, 2019. 
power over nature. When the capital was transferred, the modernist project was not adapted to the urban water cycle and new infrastructure techniques and, after 59 years, there is still a lack of planning provoking costly interventions and constructions such as those presented by NOVACAP for the problems urban drainage system. The sustainability of the capital is currently being questioned, and Brasilia is in the clash between managers of the governmental and patrimonial organs regarding the measures to address drainage problems as well as protection of soils and springs throughout the DF. Thus, the research aimed to find arguments - among those that determine the tipping of the Pilot Plan - that make possible and justify the use of more sustainable alternatives such as the spatial patterns of green infrastructures for the regions that present flood surges. The origins of the park city were investigated, considering the Bucolic Scale - within the patrimonial, historical and symbolic aspects, and the demands (water, energy, work) and resources (gray and black waters, organic and recyclable waste).

Keywords: Urban Drainage, Green Infrastructure, Bucolic Scale, Patrimony, Brasilia Water Sensitive, Pilot Plan.

\section{INTRODUÇÃO}

Esta pesquisa dá prosseguimento ao projeto intitulado Brasília Sensível a Água (Editais ProlC/UnB 2015-2016; 2016-2017), que tem como objetivo demonstrar o estado crítico de situação das águas do Distrito Federal no contexto das mudanças climáticas e do Bioma Cerrado em relação à demanda por infraestrutura ecológica para novas ocupações urbanas e restabelecimento do ciclo da água urbano.

Os primeiros registros sobre o Planalto Central onde se situaria Brasília, já continham, em 1893, estudos sobre as condições climáticas, biológicas e físicas da região, e destacavam a presença de imensa planície rodeada de chapadões, indicando à anterior existência de um lago naquele local, onde a junção de diferentes cursos d'água formava o rio Paranoá. Previstos a serem protegidos por parques e áreas verdes marginais, segundo Cardoso (2015) os mananciais já eram assunto de disputa de interesses, tendo de um lado o pensamento ambientalista de reconhecimento do valor primário da água como fonte de vida, e do outro, os desenvolvimentistas, defendendo os interesses representados pelos negócios imobiliários das cidades.

Essas disputas de interesses não deixariam de estar presente quando da transferência da capital para o Centro-Oeste, contexto histórico em que o rápido crescimento populacional nas grandes cidades demandava por moradia, saneamento e demais infraestruturas básicas à população, tornando-se motivos para medidas políticas e administrativas em torno do planejamento urbano, que, no entanto, envolviam a realização de obras grandes e onerosas ao orçamento público, com a intenção, talvez, de nos mostrarmos modernos ao mundo. Cardoso (2015) aponta que esse modernismo não se aplicou ao manejo das águas, atropelando o conhecimento a respeito dos prejuízos às fontes de água pela ausência de tratamentos adequados.

Tendo o progresso como objetivo, Juscelino Kubitschek conquistou a presidência (1955) e criou a NOVACAP já em seu primeiro ano de mandato, empresa que estaria responsável pela construção de Brasília e que teria o prazo de três anos para sua inauguração. Neste processo, foi realizado o concurso de propostas para o terreno escolhido, que deveria atender às exigências de previsão de abastecimento de energia elétrica, de água, de transporte e demais infraestruturas essenciais à vida urbana. No entanto, a proposta vencedora, apesar de o projeto ter sido concebido visando o acompanhamento das curvas de nível, não atendia a tais especificações, e seu autor, Lucio Costa, referiu-se apenas ao lago como espaço contemplativo, previsto para ser acompanhado de "bosques e campos de feição naturalista e rústica", sem especificar a importância do Lago Paranoá na melhoria das condições climáticas locais, na possível geração de energia ou, muito menos, na possibilidade de ser fonte do abastecimento de água. Essa carência de detalhes referentes às condições ambientais, o curto prazo de tempo e o deslocamento de 600 a $800 \mathrm{~m}$ do projeto em direção ao Lago impuseram soluções imediatas que posteriormente resultaram em problemas de drenagem, assoreamento e abastecimento. 
O atual embate entre gestores do órgão governamental e patrimonial gira em torno de medidas a serem tomadas no enfrentamento das mudanças climáticas e crise hídrica, como inundações, pontos de alagamentos, derrubadas de árvores, proteção de nascentes e recuperação de erosões em todo Distrito Federal.

Tendo em vista a problemática da drenagem urbana em Brasília, em outubro de 2015 foi organizada a oficina técnica "As águas pluviais e a Preservação do Conjunto Urbanístico de Brasília" pela Superintendência do IPHAN no Distrito Federal e a Associação Brasileira de Engenharia Sanitária - ABES/DF com o intuito de levantar princípios e critérios para nortear uma política pública de manejo das águas pluviais urbanas de baixo impacto ambiental. Foram discutidas soluções para harmonizar o manejo das águas pluviais urbanas com a preservação da cidade de Brasília, notando-se o interesse do IPHAN em conciliar novas técnicas de infraestrutura verde com o paisagismo da cidade de Brasília.

Dentro do contexto maior da pesquisa, que tratam dos padrões espaciais e princípios dos ciclos e fluxos da água para o desenho e planejamento de cidades mais resilientes, o objetivo principal desta pesquisa foi analisar o plano de drenagem proposto pela NOVACAP no Projeto Drenar DF e identificar, dentre as técnicas de infraestrutura ecológicas sistematizadas em pesquisas anteriores deste projeto, quais se adequariam ao Plano Piloto sem ferir a lei de Tombamento. O projeto visa dar apoio à busca por soluções não estruturais para a drenagem urbana, mesmo que os problemas de enchentes sejam sistemáticas e exijam rápida solução.

\section{MATERIAIS E MÉTODO: PATRIMÔNIO, ESCALA BUCÓLICA E INFRAESTRUTURA ECOLÓGICA}

A pesquisa teve início com a investigação histórica sobre a concepção de Brasília no Plano de Lúcio costa e posteriormente sobre a Portaria do IPHAN de $n^{\circ} 314$, de 1992, que trouxe finalmente as delimitações e primeiras diretrizes de preservação do Conjunto Urbanístico de Brasília. Com as recentes discussões do Plano de Preservação do Conjunto Urbanístico de Brasília (PPCUB), iniciadas em 2011, o IPHAN reconheceu necessidades de aprofundamento e aprovou a Portaria $n^{\circ} 166 / 16$, que traz com maior riqueza de detalhes e profundidade 0 processo de gestão, preservação e fiscalização do conjunto.

Originais do projeto piloto de Lucio Costa, são apenas as Escalas Monumental, Residencial e Gregária as que o urbanista aborda durante o I Seminário de Estudos dos Problemas Urbanos de Brasília (em 1974), lembrando-se ele da escala Bucólica como uma quarta escala, cuja integração espacial se daria entre as anteriores, mesmo que ela conte com características próprias e específicas. Mas acontece que, para medidas de fiscalização e gestão, o IPHAN insiste em definir critérios de preservação por zonas, não se adequando à organicidade da escala Bucólica.

A essência da Escala Bucólica tende a se perder a medida que os espaços livres são configurados isoladamente dentro das outras três escalas. Por exemplo: o canteiro central da Esplanada dos Ministérios, referido como escala monumental em ambas as Portarias, no documento atual é configurado como "área livre pública, gramada, com vegetação rarefeita e non aedificand". Se tratado inicialmente como bucólico, poderia indicar a um melhor aproveitamento ambiental e social da área sem prejuízo da "plena visibilidade" - esta sim essencial à preservação monumental. Da mesma forma, a Escala Bucólica é mantida, no documento, como "destinadas à preservação ambiental", isolando-a do contexto econômico, social e ambiental da cidade.

Enquanto ela é mantida como ideal de parque, sendo racionalmente produzida pela preservação e também pelos usos que nela se dão, seus custos demandam água em demasia, energia e trabalho. Os extensos gramados, que no momento do pico da chuva não infiltram a água no solo como se espera, durante a seca ficam muito secos e são constantemente cortados elevando o custo da manutenção bem como os milhares de canteiros de vias e balões, regados para manter as flores exóticas. A natureza aqui é produzida como espetáculo, como especulação do valor da terra (ou $\left.\mathrm{m}^{2}\right)$, mas é preservada pela construção do ideal de "volta à natureza".

Por outro lado, a Escala Bucólica possibilita a aplicação de tecnologias alternativas, mais 
sustentáveis e autônomas, como as de infraestrutura verde (desenvolvidas em outros PIBICs do projeto Brasília Sensível à Água, no formato de padrões espaciais, ilustrados na Quadro 1 abaixo.

Quadro 1 - Padrões de infraestrutura ecológica sugeridos ao Conjunto Urbanístico de Brasília

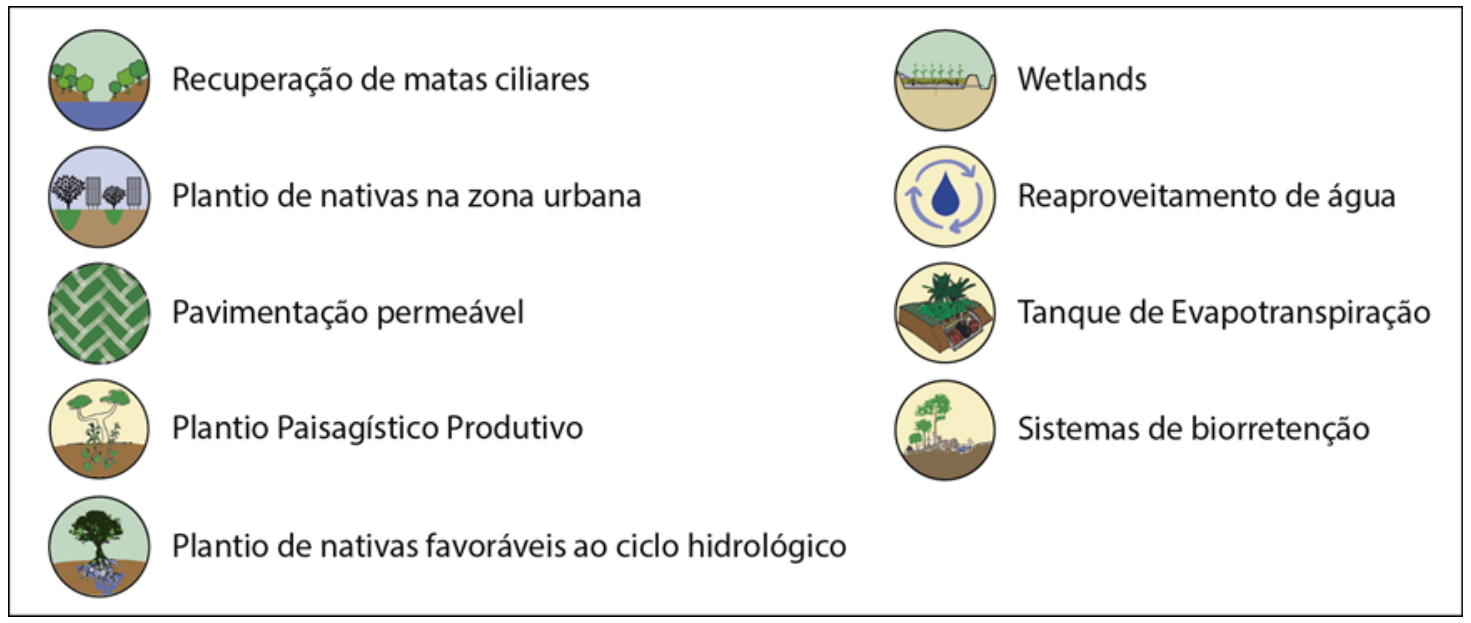

Fonte: Produzido por Raíssa Gramacho - projeto Brasília Sensível à Água

\section{RESULTADOS DA APLICAÇÃO DOS PADRÕES DE INFRAESTRUTURA ECOLÓGICA}

Resultados da análise demonstram que a cidade-parque modernista deixa a desejar quanto a sua função socioambiental, e gestores e demais agentes influentes seguem agindo sem um planejamento territorial com foco nos recursos e resíduos. A produção da natureza, é a consolidação de áreas predominantemente "verdes" e livres de ocupação como pertencentes à Escala Bucólica, alimentando o discurso utópico de uma cidade mais integrada à natureza, menosprezando a perda de biodiversidade do Cerrado. Estas extensas áreas são responsáveis pelos grandes deslocamentos, atravessadas cotidianamente por pedestres (maioria da classe trabalhadora) sem que, por isso, garantam o prazer e o conforto de um microclima natural.

A partir, então, da discussão sobre a função ambiental da terra/do imóvel, e das normas do IPHAN para intervenções no Plano Piloto, foi traçada uma unidade entre as projeções de integração da natureza vistas em Lucio Costa, com as soluções sustentáveis de drenagem já encontradas nas pesquisas do projeto Brasília Sensível à água. Assim, foram escolhidas as áreas de intervenção propostas pela NOVACAP (Figura 1), consideradas críticas, incluindo a área do Trevo de Triagem Norte, para lançamento de diretrizes sustentáveis e menos onerosas, conforme padrões de infraestrutura ecológica apresentados na metodologia com base na topografia local (SICAD/DF) e nas escalas de Lucio Costa, como elementos originais tombados. 
Figura 1 - pontos críticos da drenagem da NOVACAP e que serão ilustrados nos mapas
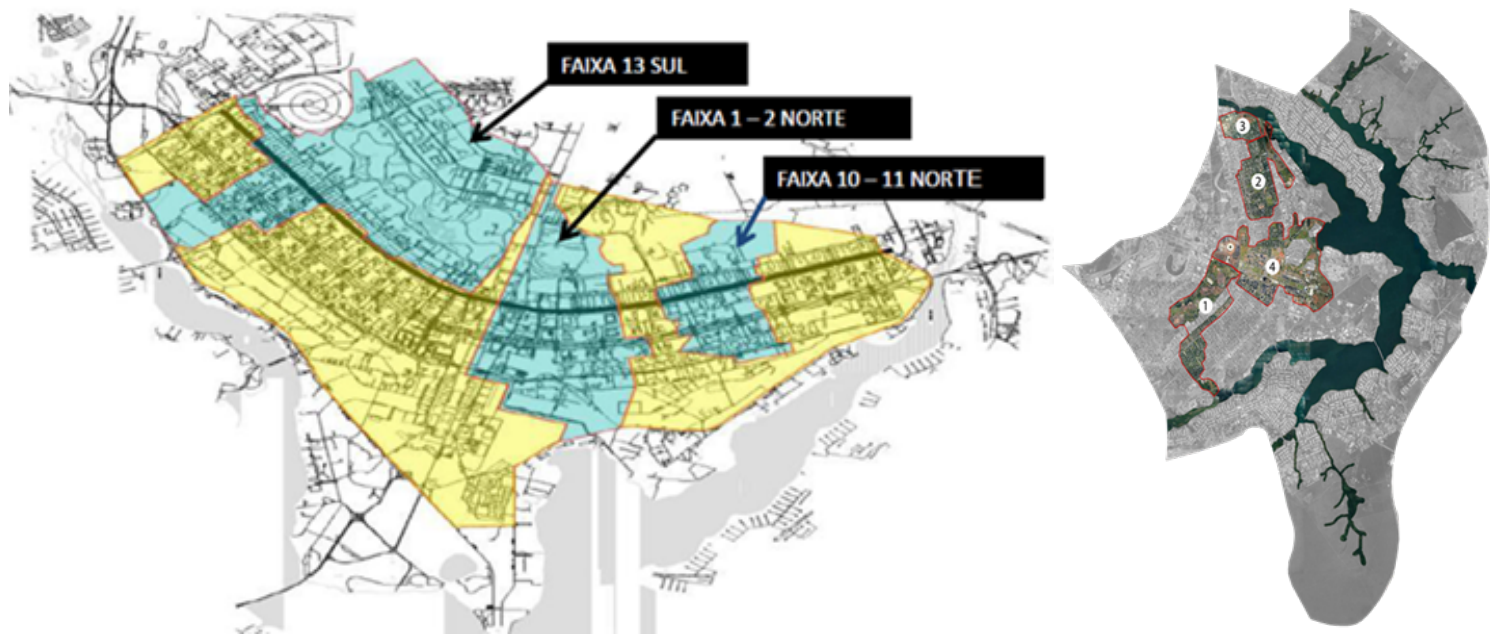

Fonte: Adaptado da NOVACAP e produzido por Raíssa Gramacho

Assim, nos espaços bucólicos da Escala Residencial predominaram soluções como o plantio de espécies nativas e paisagístico produtivo, o uso de pavimentação permeável, o reaproveitamento de água, sistemas de bioretenção e os tanques de evapotranspiração (Figuras 2, 3 e 4).

Figura 2 - Mapa: SQS $311 / 614$

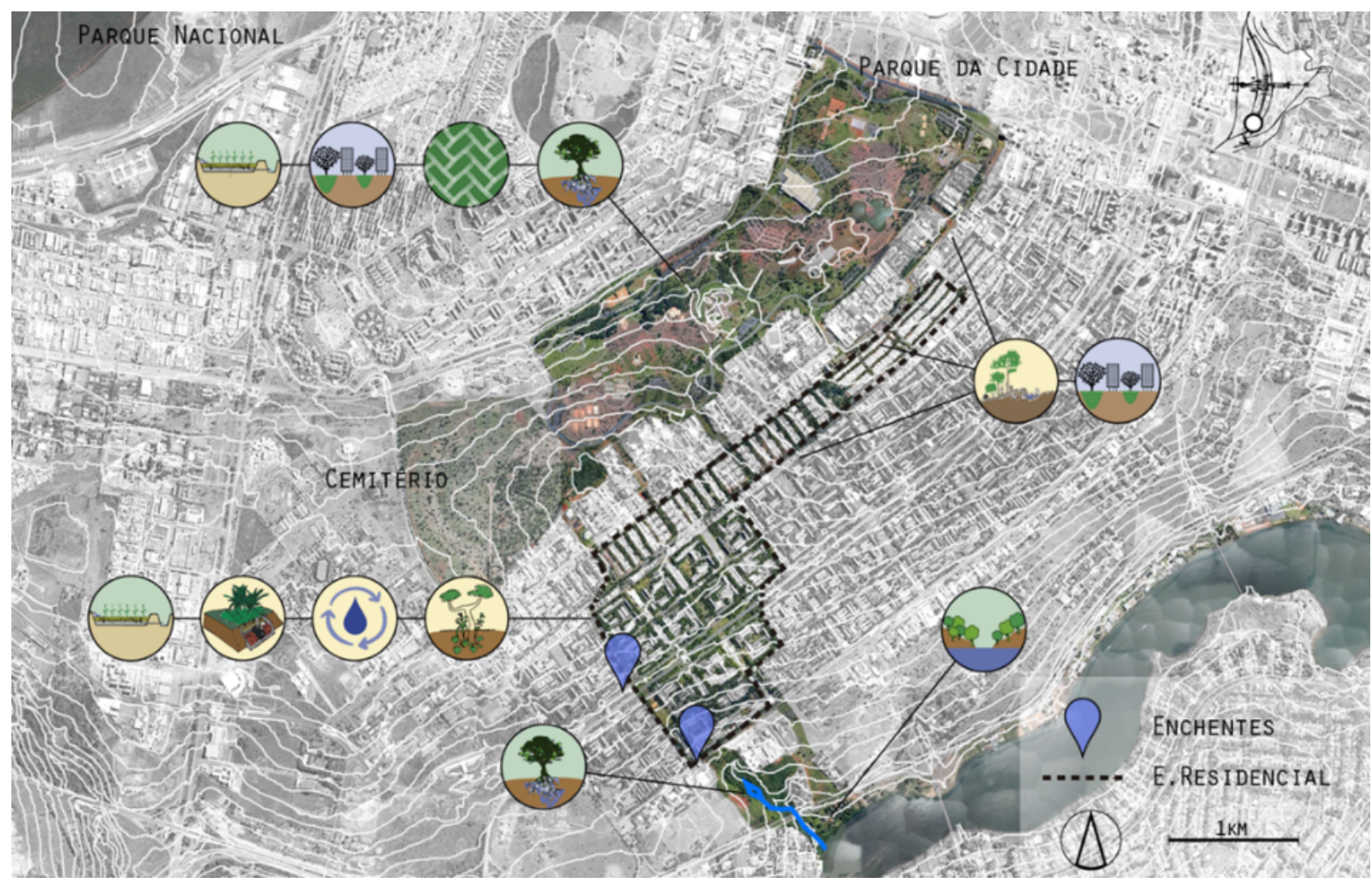

Fonte: Produzido por Raíssa Gramacho 


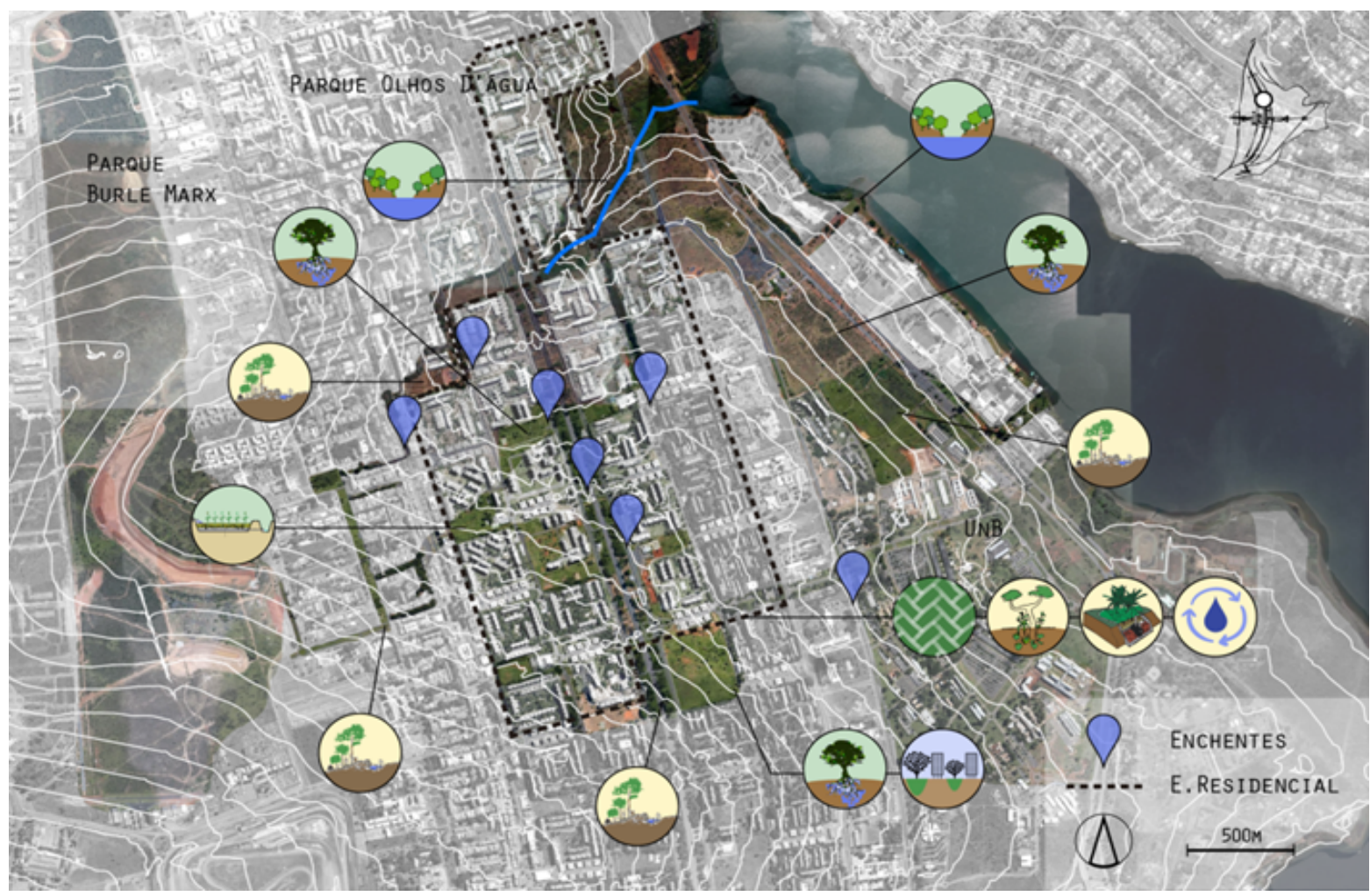

Fonte: Raíssa Gramacho

Figura 4 - Mapa: Trevo de Triagem Norte

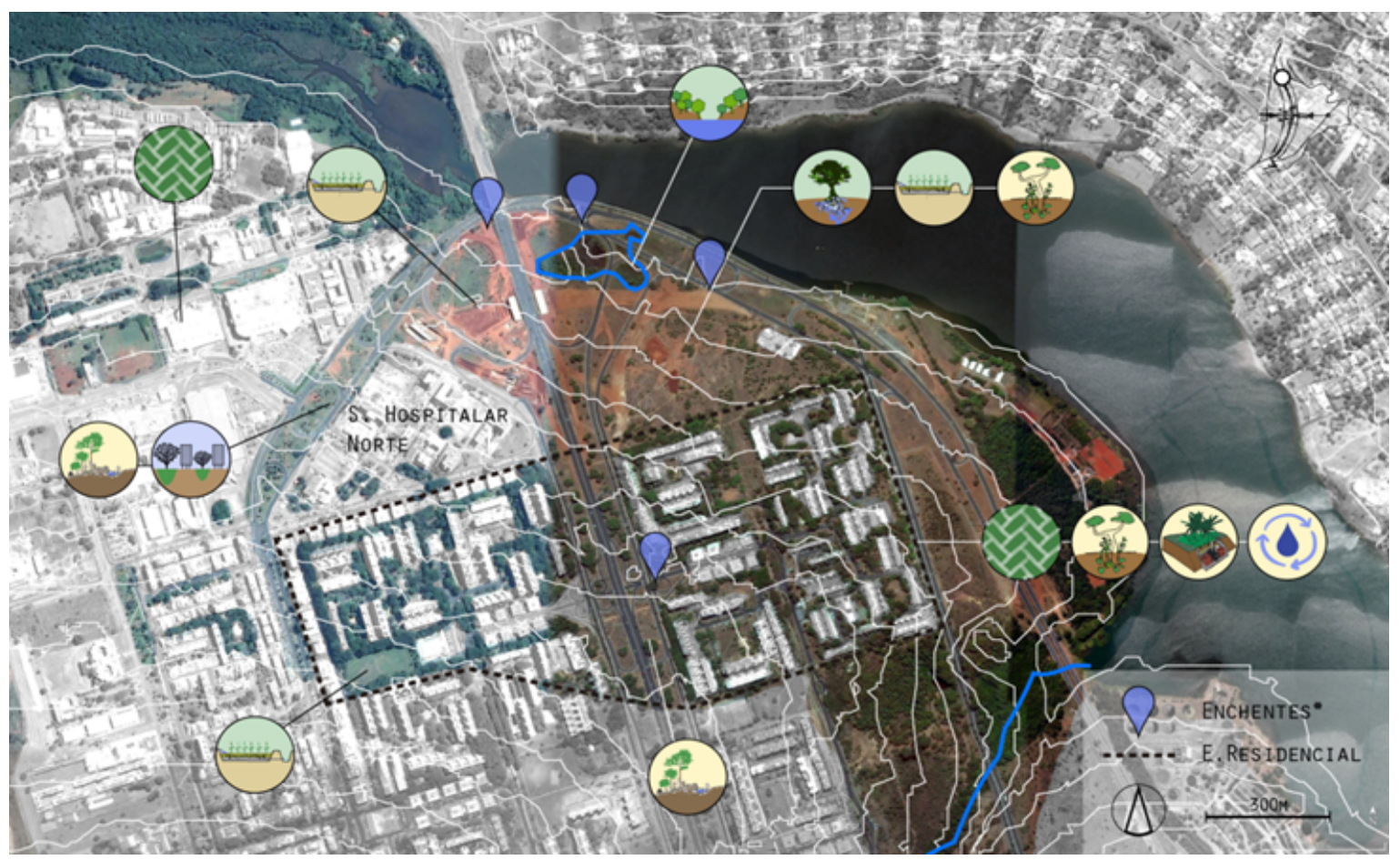

Fonte: Raíssa Gramacho

Na Escala Gregária, o ponto crítico de enchente está na impermeabilização do ponto mais alto geograficamente, pelo Estádio Nacional Mané Garrincha, o que não nos impediu de 
considerá-la como um todo, aplicando a pavimentação permeável à todas as áreas de estacionamentos (no caso do estádio, com urgência), o reaproveitamento de água, sistemas de biorretenção e o plantio de espécies nativas (Figura 5). Já na Escala Monumental, em seu trecho que cruza com as duas anteriores, o maior desafio é romper os paradigmas do paisagismo de jardins gramados para incluir wetlands, sistemas de biorretenção e plantio de espécies favoráveis à nossa hidrologia, como soluções drenantes, e o reaproveitamento de água com cisternas de água da chuva e com tanques de evapotranspiração, almejando que a monumentalidade seja mais autônoma quanto sua demanda de recursos..

Figura 5 - Mapa: Eixo Monumental, Setores Comerciais e Hoteleiros, e SQN 902/602

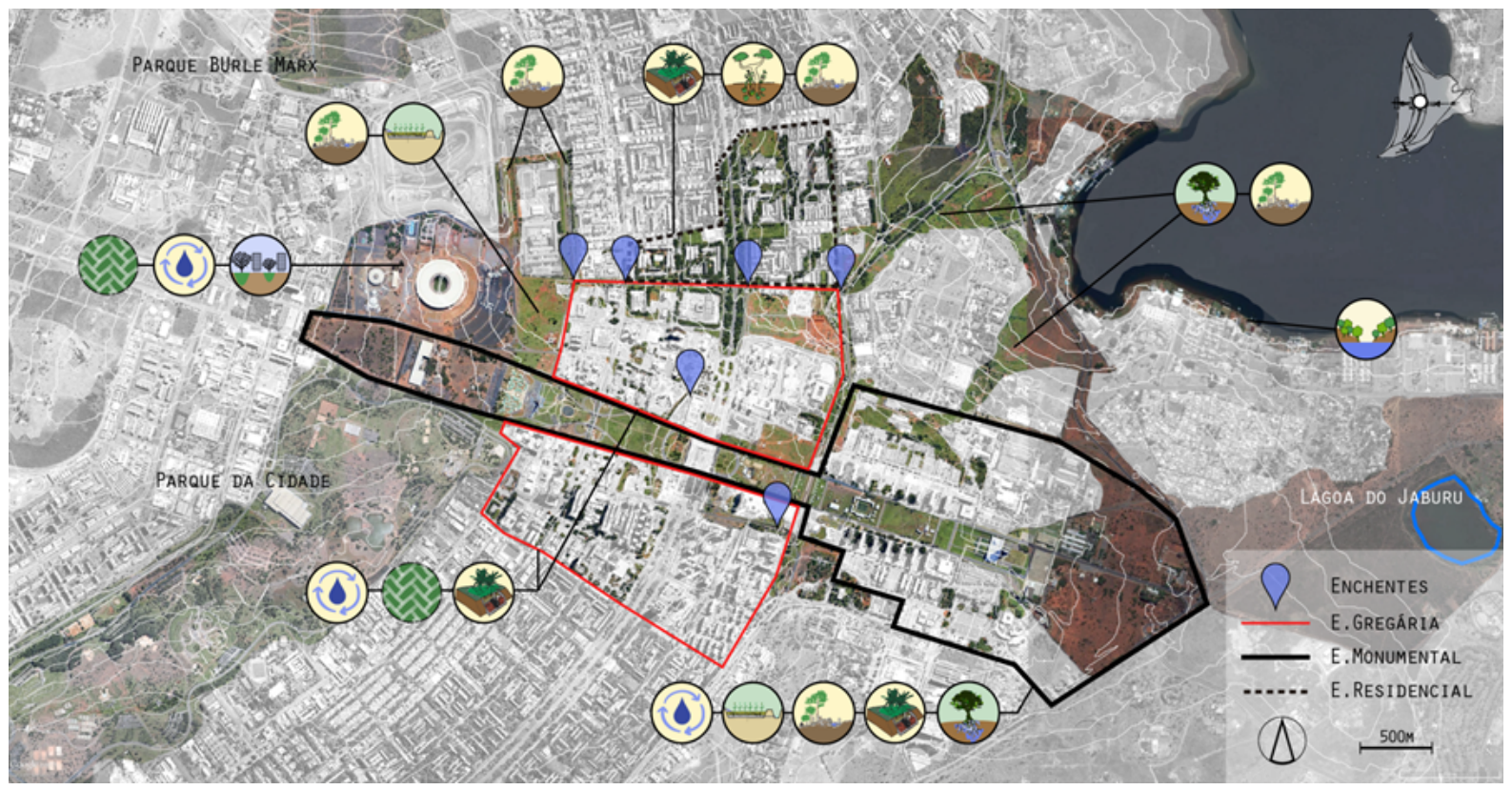

Fonte: Raíssa Gramacho

\section{CONCLUSÕES}

A Escala Bucólica é a totalidade dos espaços livres e deve ser qualificada como tal, atendendo às necessidades econômicas, sociais e ambientais da cidade; e ao mesmo tempo é parte da totalidade ecossistêmica da Bacia do Paranoá, na qual espera-se contribuir com sua diversificação. Reconhecemos ser um desafio para as instituições de patrimônio se adaptarem às questões ambientais, inclusive de patrimônio natural (contando com a água). Mas o contexto único de Brasília - que tem três dos quatro elementos fronteiriços de sua área tombada como elementos hídricos - exige delas uma renovação de valores e a defesa destes, posto que a escala bucólica é constituída também de áreas de preservação ambiental.

Nenhuma das soluções está isolada das outras, sendo propostas como ressignificadoras da Escala Bucólica, permitindo que uma "outra" natureza seja produzida a partir das demandas reais e ambientais da cidade. As diretrizes propostas não interferem nas exigências da Portaria $n^{\circ}$ 166/16 (IPHAN), posto que se dão dentro dos espaços e das características orgânicas da escala bucólica, agregando o Cerrado da cidade-parque.

\section{REFERÊNCIAS}

ANDRADE, Liza Maria Souza de; LACERDA, Guilherme; OLIVEIRA, Alessandra; OLIVEIRA, Adriane; CAMARGO, Pedro; DANTAS, André. Brasília Sensível à Água. In: Encontro da Associação Nacional de Pesquisa e Pós-Graduação em Arquitetura e Urbanismo. Anais... Porto Alegre: 2016. 
ANDRADE, Liza Maria Souza de; LACERDA, Guilherme; OLIVEIRA, Alessandra; OLIVEIRA, Adriane; CAMARGO, Pedro; DANTAS, André. Brasília Sensível à Água: a situação crítica das águas no DF em relação ao ciclo da água urbano e à demanda por infraestrutura ecológica. In: SINGEURB 2017, São Carlos, 2017.

BRASIL. Portaria $\mathbf{n}^{\circ}$ 314, de 08 de outubro de 1992. Disponível em < http://www.iphan.gov.br/>. Acesso em: 15 de setembro de 2016.

BRASIL. Portaria $\mathbf{n}^{\circ}$ 166, de 11 de maio de 2016. Disponível em < http://www.iphan.gov.br/>. Acesso em: 15 de setembro de 2016.

CAMARGO, Pedro Rodolpho Ramos; ANDRADE, Liza Maria Souza; Ribeiro, Rômulo. Drenagem Urbana no DF: novas demandas por infraestrutura ecológica frente ao futuro incerto de escassez de água. PIBIC, Universidade de Brasília, 2016.

DANTAS, André Luís de Faria; ANDRADE, Liza Maria Souza de Andrade; RIBEIRO, Romulo. 0 uso da água: as hortas urbanas e jardins agroflorestais no DF. PIBIC, Universidade de Brasília, 2016.

GOVERNO DE BRASÍLIA. Plano Distrital de saneamento básico e de gestão integrada de resíduos sólidos. Brasília: julho/2017

JORNAL OPÇÃO. O cerrado está extinto e isso leva ao fim dos rios e dos reservatórios de água. Disponível em: <http://www.jornalopcao.com.br/entrevistas/o-cerrado-esta-extinto-eisso-leva-ao-fim-dos-rios-e-dos-reservatorios-de-agua-16970/>. Acesso em: 19 jul. 2016.

JÚNIOR, Wilde Cardoso Gontijo. Águas em Brasília: ainda não somos modernos!. Brasília em debate, Brasília, p. 16-24, 2015

NERY LACERDA, Guilherme; DE ANDRADE, Liza; RIBEIRO, Romulo. Novos padrões urbanos de saneamento ecológico: alguns casos bem sucedidos no DF e a relação com a saúde ambiental. PIBIC, Universidade de Brasília, 2016.

OLIVEIRA, Alessandra Adriane Barbosa; DE ANDRADE, Liza Maria Souza de Andrade; RIBEIRO, Romulo. O Ciclo da água no Cerrado: novos padrões urbanos para reestabelecer $O$ equilíbrio do trinômio solo-vegetação-atmosfera. PIBIC, Universidade de Brasília, 2016.

PERPÉTUO, Thiago Pereira. Uma cidade construída em seu processo de patrimonialização: modos de narrar, ler e preservar Brasília. Mestrado, Instituto do Patrimônio Histórico e Artístico Nacional, 2015.

SMITH, Neil Desenvolvimento desigual: Natureza, capital e a produção do espaço. Rio de Janeiro: Bertrand Brasil S.A., 1988. 